\title{
ЭКОНОМИЧЕСКОЕ ОБРАЗОВАНИЕ В ВОСТОЧНОЙ СИБИРИ В КОНТЕКСТЕ МОДЕРНИЗАЦИОННЫХ ПРОЦЕССОВ ХХ ВЕКА. РАЗМЫШЛЕНИЯ НАД КНИГОЙ А. П. СУХОДОЛОВА И Д. Я. МАЙДАЧЕВСКОГО*
}

\author{
В. Н. Казарин \\ Иркутский государственный университет, г. Иркутск, Российская Федерация
}

Информация о статье

Дата поступления

12 января 2018 г.

Дата принятия к печати

28 фревраля 2018 г.

Дата онлайн-размещения

30 марта 2018 г.

Ключевые слова

Экономическое образование;

Восточная Сибирь;

«университетский вопрос»;

модели высшего образования

\begin{abstract}
Аннотация
Статья посвящена анализу монографии А. П. Суходолова и Д. Я. Майдачевского по проблеме становления и развития экономического образования в Восточной Сибири. Отмечено, что авторы рассмотрели необходимость и предпосылки формирования коммерческих училищ, экономическое образование в 1920-е гг. в Иркутском государственном университете, создание Сибирского финансово-экономического института и его дальнейшую эволюцию. В статье освещены дискуссионные вопросы о модели создания сибирского университета, о соотношении «академического» и «прагматического» направлений в подготовке специалистов, о судьбах университетского образования в регионе, о новых задачах в системе высшего образования на сегодняшний день. Сделан вывод о том, что монография является заметным вкладом в современную историографию истории образования и науки в Сибири.
\end{abstract}

\section{ECONOMICS EDUCATION IN EASTERN SIBERIA IN THE CONTEXT OF MODERNIZATION PROCESSES OF THE 20 ${ }^{\text {TH }}$ CENTURY. THOUGHTS ON THE BOOK BY ALEXANDER SUKHODOLOV AND DMITRY MAIDACHEVSKY}

Victor N. Kazarin

Irkutsk State University, Irkutsk, the Russian Federation

Article info

Received

January 12,2018

Accepted

February 28, 2018

Available online

March 30, 2018

\section{Keywords}

Economics education; Eastern Siberia; 'university' issue; higher education models

\begin{abstract}
The article is devoted to the analysis of the monograph by Alexander Sukhodolov and Dmitry Maidachevsky on the problem of the making and development of economics education in Eastern Siberia. It is noted that the authors addressed the necessity and prerequisites for the formation of commercial schools; economics education in the Irkutsk State University in the 1920s; the foundation of the Siberian Financial and Economic Institute and its further evolution. The article highlights debatable questions about the model of the making of the Siberian university, the correlation of the «academic» and «pragmatic» directions in the training of specialists, the fate and fortunes of university education in the region, and the new tasks in the system of higher education to date. The author makes a conclusion that the monograph is a significant contribution to the modern historiography of the history of education and science in Siberia.
\end{abstract}

Рецензия на кн.: Суходолов А. П., Майдачевский Д. Я. «Храм науки» или «фрабрика кадров»: к историческим предпосылкам дискуссии об опорном университете Байкальского региона. Иркутск : Изд-во БГУ, 2017. 92 с. / Book review: Sukhodolov A. P., Maidachevsky D. Ya. «The Sanctuary of Sciences» or «Personnel Factory»: Historical Background of the Discussion about the Basic University of Baikal Region. Irkutsk : Baikal State University Press, 2017. 92 p. 
1907 год - начало экономического образования в регионе. Прошедший 2017 год явился памятным в истории образования и подготовки кадров для Восточной Сибири. К этой дате было приурочено издание книги «Храм науки» или «фабрика кадров»: к историческим предпосылкам дискуссии об опорном университете Байкальского региона». Ее авторы - ректор Байкальского государственного университета, заслуженный экономист Российской Федерации, доктор экономических наук, профрессор А. П. Суходолов и доцент этого же университета, кандидат экономических наук Д. Я. Майдачевский, известные своими публикациями, в том числе и по истории экономической мысли и образования. Следует отметить, что основу издания составили статьи авторов, опубликованные в журнале «Известия Байкальского государственного университета» в 2016-2017 гг. [1-4].

Эта книга продолжает ряд работ, посвященных истории высшего экономического образования в Восточной Сибири в целом и в Иркутске в частности. Среди изданий, вышедших в обозримом прошлом, можно отметить краткий исторический очерк об Иркутской государственной экономической академии [5], издания справочного характера [6; 7], монографию, специально посвященную научной деятельности в этом вузе от его возникновения до конца XXв. [8], научно-публицистический сборник, состоящий из очерков, рассказов и эссе о ведущем экономическом вузе страны [9] и др. При этом может возникнуть впечатление «перенасыщенности» темы. Такое чувство иногда появляется при чтении публикаций на определенную тему с высокой степенью повторяемости рассматриваемых сюжетов. Но рецензируемое издание существенно отличается от предшествующих. Это не справочное издание и не привычно написанная история вуза. Авторы рассмотрели не только основные вехи развития Иркутского финансово-экономического института/Байкальского государственного университета, но и изложили предысторию вуза, появление учебных заведений экономического профиля. Все это представлено панорамно, на фоне и в контексте наиболее значимых социально-политических событий, модернизационных вызовов минувшего века. Книгу отличает также не плавное «академическое» изложение исследуемой темы, а дискуссионность подачи материала, временами даже обострение некоторых проблемных вопросов в истории высшего профрессионального образования в регионе. Очевидно, это можно объяснить как проблемностью в освещении предысто- рии «университетского вопроса» в Иркутске, так и общей атмосферой развития высшего образования в стране в целом, вызванной полемикой вокруг опорного вуза в областном центре. Полемикой, как сейчас представляется, созданной несколько искусственно стараниями не столько учредителя вузов, сколько средствами массовой инфрормации и эмоциональными обсуждениями в социальных сетях. Сейчас, когда «страсти» поутихли, а ситуация относительно стабилизировалась, можно рассмотреть содержательную, основную сторону книги, определить, насколько возможно, ее вклад в историографическую традицию региональной научно-образовательной тематики.

Итак, каков жанр книги? Публицистическое издание, вышедшее в этот «особенный» для высшей школы, как указано выше, непродолжительный период, или небольшая монография со всеми присущими ей атрибутами, написанная проблемно, живым языком в полемическом ключе? Очевидно, что такая формулировка также несколько полемична. Вопрос о жанре печатной продукции и компетентности ее авторов в последнее время стал одним из острейших, поскольку на книжном рынке, не говоря уже о некоторых информационных материалах в Интернете, появилось немало слабо документированных или не документированных вообще материалов.

Книга А. П. Суходолова и Д. Я. Майдачевского, безусловно, является документированным изданием, написанным профрессиональными исследователями, в течение многих лет занимающимися этой или близкой проблематикой. Авторы привлекли 84 относимых к теме источника, среди которых газетные материалы, журнальные статьи, монографические исследования за последние более чем сто лет. Содержание книги усилено и, можно сказать, украшено фотографиями, в том числе редкими, среди которых выдержки из газеты «Власть труда», «Восточно-Сибирская правда», сюжетные фотографии из жизни вуза, снимки выдающихся выпускников.

Монография включает все компоненты: введение, основную часть, заключение и список использованной литературы. Основу книги составили три небольших раздела. Основное деление содержания монографии - проблемно-хронологическое, хотя авторы допускают некоторые «хронологические ретроспекции» в последующем изложении темы. Скорее, композиция книги проблемно-дискуссионная, что, исходя из замысла авторов, делает ее вполне оправданной. 
Первый раздел авторы посвятили освещению вопроса о зарождении коммерческого образования в России, справедливо указав, что оно появилось как ответ на структурную модернизацию страны, ассоциируемую с именем министра фринансов С. Ю. Витте. Его идея создания коммерческих и технических институтов, которые «имели бы организацию не технических школ, а университетов», вполне здравая и своевременная, отвечала насущным государственным запросам. Правда, в Сибири она начала реализовываться не созданием институтов, а открытием коммерческих училищ. В Иркутске Устав городского коммерческого училища по подготовке специалистов средней квалификации для торговли и промышленности был утвержден министром торговли и промышленности 9 августа 1907 г. Фактически училище стало осуществлять образовательную деятельность с 1 сентября 1908 г. Именно с 1907 г. авторы отсчитывают начало экономического образования в регионе, хотя, заметим, между училищем де-юре и училищем де-фракто прошло более года. Случай не такой уж редкий: томичи тоже называют две даты - 1876 и 1888 гг. (год принятия решения и год фрактического начала ффункционирования университета в составе одного факультета - медицинского). Можно отметить также, что судебные уставы были подписаны императором Александром II в 1864 г., а фрактически судебная реформа началась в России только в 1866 г., хотя везде именуется реформой 1864 г. Поэтому 1907 г., исходя из имеющихся подходов, можно считать началом экономического или, по терминологии того времени, коммерческого (в статусе среднего специального, как мы говорили долгое время) образования. Этим утверждением я косвенно отвечаю некоторым из коллег, которые указывали мне на то, что началом следует считать 1908 г., а с годом ранее несколько поспешили. Можно считать началом принятие юридического документа, положения которого были реализованы в исторически краткий срок.

В этом же разделе авторы рассматривают дальнейшую судьбу коммерческого образования в Иркутске: с восстановлением советской власти в 1920 г. коммерческое училище стало школой второй ступени, но в 1921 г. на ее основе стал функционировать Иркутский практический промышленно-экономический институт, включенный в 1924 г. в состав фракультета права и местного хозяйства Иркутского государственного университета.

Второй раздел, наибольший по объему, освещает несколько сюжетов. Авторы под- нимают дискуссионные вопросы, анализируя сложные пути развития экономического образования в Иркутске в 1920-1930-е гг. Тематика раздела рассматривается авторами через соперничество двух линий: классической модели «чисто научного» университета и «новой» модели, ориентированной на решение «прагматических» задач. В рамках этого подхода внимание обращено на дискуссию, проходившую на страницах региональных изданий между сторонниками того и иного направлений, а также на перипетии экономического образования на факультете общественных наук, а затем фракультете права и местного хозяйства в Иркутском государственном университете.

Третий раздел посвящен экономическому образованию уже в Иркутском финансово-экономическом, ставшим позже (1965г.) институтом народного хозяйства. Авторы убедительно показали необходимость расширения специальностей подготовки, укрепления кадрового состава вуза и повышения его потенциала.

Как отмечалось, рецензируемое издание поднимает ряд дискуссионных вопросов, привлекая научную общественность к их обсуждению. Один из них - каким должно быть высшее учебное заведение в Иркутске? В частности, приведено высказывание редактора красноярского журнала «Сибирские записки» В. М. Крутовского в статье «Вопрос об университете» на исходе 1916 г., в которой встречается фраза о том, что «впереди стоит период широкого промышленного развития», а оставлять «старый университет в его настоящем виде или открывать новый по типу захудалого храма науки (курсив мой. - В. К.), дескать, для отдаленной провинции и такого достаточно, и нерационально, и для Сибири будет достаточно». Приведено и высказывание директора Иркутского коммерческого училища И. М. Камова, также за 1916 г., в «Иркутской жизни» о том, что «нужда в людях, обладающих прикладными знаниями, прямо вопиющая». Следует ли отсюда, что существовала резкая полемика между сторонниками «чисто научного» учебного заведения и нового - «практико-ориентированного» (сельскохозяйственного, политехнического и (или) экономического институтов)?

Обратимся к источникам тех лет. В книге приведена позиция директора Иркутского коммерческого училища И. М. Камова, поддерживавшего идею создания в Иркутске университета и в то же время указывавшего на нужду в людях, «обладающих прикладными знаниями» $[10$, с. 16]. Но насколько 
это противоречило другим высказываниям - модели будущего университета? Обратимся к статье Ф. Ширяева, опубликованной в 1915 г. в «Известиях ВСОРГО». Основу статьи составило его выступление на общем собрании членов ВСОРГО 27 октября 1912 г. Конечно же, это совпадение, но интересно то, что выступление состоялось ровно за шесть лет до дня открытия второго сибирского университета. И вот что сказал знаток «университетского вопроса»: «По разнообразию составляющих его наук, университет более всякой другой школы со специально-техническими знаниями мог бы, с одной стороны, удовлетворять разнообразным образовательным потребностям сибирского юношества, а с другой - вести постоянно и систематически вышеупомянутое исследование, которое осталось бы, как и прежде, на руках более или менее случайных и редких ученых экспедиций». И далее Ф. Ширяев указывает на то, что «соседство в одной и той же школе науки чистой и прикладной есть дело вполне возможное», т. е. университет может быть и проводником «необходимых прикладных знаний» [11, с. 66]. Можно приводить и другие примеры для наиболее полного отражения высказываний относительно модели будущего университета. Что же касается фрразы о «захудалом храме науки», то это контекстуальное высказывание является скорее желанием избежать создания такого типа заведения в Сибири, но уж никак, даже близко, констатацией того, что было реально создано. Напомним, что фраза прозвучала в 1916 г. , за два года до появления университета. На наш взгляд, дискуссия в печати - это вполне нормальное отражение состязательности различных мнений, из которых одни находят свое воплощение в исторически близкий период, другие имеют «отложенную судьбу», а третьи просто забываются за невостребованностью.

Другой момент, который привлекает внимание, - это использование в книге применительно к Иркутскому университету прилагательного «городской» [10, с. 21, 23, 51]. При этом ни в одном официальном документе, ни в газетных статьях того времени, которые достаточно полно представлены в книге, ни в многочисленных сборниках тех лет, выступлениях представителей власти и преподавательского корпуса такого словосочетания, как «Иркутский городской университет», нигде нет. Что же следует понимать под таким определением? Если трактовать это таким образом, что на момент активной подготовки к открытию университета (1917-1918 гг.) власть Восточной Сибири постоянно менялась [12], а инициатива в учреждении университета перешла к местному городскому самоуправлению и общественности, то это скорее должно быть точно привязано к конкретному времени. Очевидно, что в условиях смены власти, приводящей к фактической хаотизации управления в распавшейся Российской империи, происходило перераспределение подчиненности всех учреждений, субъектов публичного права. Управление сосредоточивалось на местах для того, чтобы сохранить то, что было создано ранее. Что же в этом удивительного?

Если речь идет о городском фринансировании, то таковое имело место, но в ограниченный сложный период перехода от одной власти к другой после падения колчаковского режима. Если понимать так, что университет городской и «недотягивал» до уровня государственного, то для этого нет оснований, поскольку университет готовил специалистов не для города, а для обширного региона Восточной Сибири и Дальнего Востока по историко-филологическому, востоковедному, юридическому, физико-математическому, медицинскому, педагогическому, и экономическому в том числе, направлениям подготовки. Понятия «городское училище», «городская гимназия» были официальны, но городские университеты встречались крайне редко применительно к частным учебным заведениям до 1917 г. Эта эпоха в 1920-е гг. уже ушла в прошлое.

Еще один важный вопрос, нашедший отражение на страницах рецензируемой книги, - это освещение одного из переломных моментов в истории советской высшей школы на рубеже 20-30-х гг. XX в., в том числе в истории Иркутского университета. В книге речь идет о «ликвидации самого университета» со ссылкой на то, что «историография вуза старается обходить стороной этот факт его «биографии» $[10$, с. 18,52$]$. Обратимся к документированности такого утверждения. Авторы ссылаются на одно из юбилейных изданий 1998 г. [13, с. 68-69]. Действительно, в этой «Хронике событий», а не в исследовательском труде, о фракте прекращения функционирования университета и его восстановлении говорится мало и бессистемно. На это справедливо обратили внимание исследователи. Но давайте, во-первых, расширим источниковую основу для объяснения данного фракта, а во-вторых, рассмотрим его в контексте всей научно-образовательной политики Советского государства периода 
«великого перелома». Итак, отрицался ли фракт расорормирования университета? Обратимся к одному из первых систематизированных, хотя и относительно небольшому по объему изданию еще 1978 г. Там прямо указано: «Иркутский университет, ранее подвергавшийся перестройке, в 1930 г. был расфрормирован» [14, с. 30]. О расфоормировании университета говорится и в более позднем издании [15, с. 49].

Теперь привяжем это событие к контексту модернизационного процесса, который происходил в стране на рубеже 1920-1930-х гг., именуемого по-разному (форсированный рывок, сталинская модернизация, прагматический поворот, наконец). В соответствии с решениями июльского (1928 г.) Пленума ЦК ВКП(б) «Об улучшении подготовки специалистов» и ноябрьского (1929 г.) Пленума ЦК партии «О кадрах народного хозяйства» произошла радикальная структуризация высшей школы. По существу, это означало ликвидацию университетов и переход к отраслевым вузам. На базе Томского университета, старейшего в Сибири, были образованы педагогический и медицинский институты. Химический и геологический факультеты ТГУ и Сибирского технологического института (Томск) были преобразованы в химико-технологический и геолого-разведочный институты. Такому преобразованию подверглись не только университеты, но и «прагматические» институты. Крупнейший в Сибири технологический институт в Томске был разделен на механический, инженерно-строительный и металлургический, угольный институты, а также институт сельскохозяйственного машиностроения, институт инженеров транспорта. Крепкий в организационном и кадровом отношении Омский сельскохозяйственный институт стал площадкой, на которой открыли четыре вуза: институт молочного хозяйства, институт зернового хозяйства, институт организации территории (все - в Омске) и лесотехнический (в Красноярске) [16, с. 234-235]. Что из этого получилось? Создание узкопрофрильных («карликовых») учебных заведений со слабой материальной базой привело к обострению и без того сложного положения с кадровым обеспечением, падению качества образования. Вскоре положение пришлось срочно исправлять - избавляться от мелких институтов и (или) объединять их в крупные учебные заведения. Так что Иркутский университет постигла та же участь. Его расорормирование отражало реализацию тогдашней научно-образовательной политики, которую кое-кто позднее называл «левацким перегибом», а не признаком его несостоятельности. Уже в апреле 1931 г. было принято постановление ЦК ВКП(б) «О целевых установках университетов» и в июне 1931 г. - постановление Совнаркома РСФСР об университетах в Российской Федерации, в соответствии с которыми восстанавливалась система университетов, перед которыми были поставлены новые задачи по модернизации страны. Именно поэтому и был восстановлен Иркутский (под названием Восточно-Сибирский) университет. Восстановлен на материальной и кадровой базе прежнего университета, но в составе уже химического, почвенно-географического и физического отделений, преобразованных в 1933 г. в самостоятельные факультеты. Были ли другие варианты решения проблемы? Теоретически да. Первый: объединить вновь все основанные на базе университета институты, в том числе и хорошо стартовавший Сибирский финансово-экономический институт, и другие вузы под «одну крышу». Но эти вузы, в отличие от некоторых в Западной Сибири, уже «встали на крыло», показав свою жизнеспособность. Второй: вновь вернуться к той дореволюционной «классической» модели и создавать гуманитарные отделения / факультеты. Но модернизационный вызов требовал специалистов, обладающих фундаментальными и прикладными знаниями для индустриализации страны. Ведь правильность и своевременность задачи, поставленной руководителем государства И. В. Сталиным, за десять лет сделать столько, сколько другие страны делали за кратно превышающий срок («либо нас сомнут»), - подтверждена Историей. Почему университет стал называться Восточно-Сибирским, а не Иркутским? Потому, очевидно, что это название точнее отражало происходившие тогда административно-территориальные изменения [17]. Финансово-экономический институт стал именоваться Сибирским. Возможно, эти названия отражали то, что они признавались опорными для региона? А вскоре они стали называться соответственно Иркутскими, может быть, потому, что в 1937 г. была образована Иркутская область?

И еще один момент - содержание программ экономического образования в Иргосуне во второй половине 1920-х гг. Этот сюжет занимает немалое место в книге; при этом отмечены «искания» учебных планов, «отвечающих целевой установке факультета», поиск «новых методов преподавания», «отсутствие детальной специализации в 
определенных практических областях» [10, с. 43-45]. В то же время в рамках Сибирского финансово-экономического института, благодаря во многом роли первого директора Ф. И. Чудновского, практико-ориентированное промышленно-экономическое образование «возвратилось» в Иркутск [там же, с. 51]. Значительная роль Ф. И. Чудновского в организации СФЭИ не только не отрицается, но и, напротив, акцентируется в новейшей историографии [16, с. 236].

Представляется, что на ситуацию можно посмотреть и следующим образом: учебные программы по экономическим специальностям отражали реалии нэпа со всеми его изломами, кризисами и непоследовательностью. Упор был сделан на изучение кооперации и подготовку кадров для нее. Долго ли просуществовала кооперация? Индустриализация страны, создание промышленных предприятий и необходимых при них финансово-экономических служб поставили на повестку дня подготовку специалистов данного профиля и появление новых программ, практико-ориентированных. 1920-е годы отмечены также поиском различных форм обучения, далеко не во всем себя оправдавших. От многих потом пришлось просто отказаться за их неэффективностью. От этом говорили еще современники, знающие проблемы высшей школы, что называется, изнутри.

Весь путь развития высшего образования в России в последние десятилетия показывает, что определяющей тенденцией является создание многопрофильного, а не специализированного учебного заведения ${ }^{1}$. Иркутский политехнический институт в 1990-е гг., создав подразделения гуманитарного и экономического профилей, стал техническим университетом, получив позднее статус национального исследовательского. Возникший в 1930 г. в статусе Сибирского финансово-экономического института, в 1939 г. переименованный в Иркутский фринансово-экономический институт, в 1965 г. ставший институтом народного хозяйства, в 1993 г. получивший статус государственной экономической академии, в 2002 г. превратившийся в Байкальский государственный университет экономики и права, Иркутский «нархоз» в 2015 г. преобразовался в многопрофильный Байкальский государственный университет, осуществляющий подготовку по широкому спектру подготовки бакалавров, магистров и аспирантов. Таким

${ }^{1}$ Современный университет: образование, наука, культура : материалы междунар. науч.-практ. конф. Иркутск, 2005. 396 с. образом, начав с коммерческого среднего специального образования, пройдя стадии развития в рамках Иркутского университета в 1920-е гг., осуществив «прагматический поворот» как ответ на модернизационные вызовы 1930-1950-х гг. советской эпохи, экономическое образование Восточной Сибири стало составной частью направлений высшего профессионального образования Байкальского государственного университета, готовящего кадры в том числе для правоохранительных органов, информационной и экономической безопасности, лесных и водных экосистем, СМИ и др. [18]. И это тоже «прагматический поворот», адекватно отвечающий на новые требования времени. Эта модель классического университета присуща и другим университетам, идущим в тренде модернизационных процессов сегодняшних и завтрашних лет.

В заключение необходимо отметить, что бытовавшие ранее опасения по поводу дальнейшего сокращения количества иркутских вузов потеряли, как представляется, на данный момент актуальность. Вопрос об опорных вузах решается самой жизнью, а именно востребованностью тех или иных направлений подготовки бакалавров и магистров, тем более что нормативной и правовой проработки понятия «опорный вуз» нет. Перед университетами, в том числе иркутскими, стоят новые модернизационные задачи: сохранения научного наследия и интеллектуального потенциала в условиях интеграции в мировое образовательное пространство, обеспечения многоуровневой системы подготовки кадров, реализации идеи непрерывного образования, использования новейших технологий в системе образования, усиления контроля качества подготовки выпускников вузов и повышения их конкурентоспособности на рынке труда, усиления воспитательной работы в образовательном процессе и др.

Что же касается рецензируемого издания, то это, безусловно, заметное событие в изучении истории науки и образования в регионе. Монография А. П. Суходолова и Д. Я. Майдачевского, рассмотренные в ней вопросы оценки и переоценки уже изученных явлений обладают научной и историографической новизной, побуждают не просто «считывать» информацию, а размышлять над ней. Высказанные выше соображения по дискуссионным вопросам выступают своеобразными «реперными» точками для дальнейшего исследования этой обширной тематики. 


\section{СПИСОК ИСПОЛЬЗОВАННОЙ ЛИТЕРАТУРЫ}

1. Суходолов А. П. «Прагматический поворот» траектории развития высшей школы: уроки истории / А. П. Суходолов, Д. Я. Майдачевский / / Известия Байкальского государственного университета. - 2016. T. 26, № 2. - С. 167-174.

2. Суходолов А. П. Высшая школа региона: «храм науки» против «фабрик кадров» (1920-1930-е годы) / А. П. Суходолов, Д. Я. Майдачевский / / Известия Байкальского государственного университета. - 2016. Т. 26, № 4. - С. 525-533.

3. Суходолов А. П. Высшая школа региона: «храм науки» против «фрабрик кадров» (1920-1930-е годы)/ А. П. Суходолов, Д. Я. Майдачевский / / Известия Байкальского государственного университета. - 2016. Т. 26, № 5. - С. 693-704.

4. Суходолов А. П. Экономическое образование России и региона: ответ на модернизационные вызовы середины XX века / А. П. Суходолов, Д. Я. Майдачевский // Известия Байкальского государственного университета. - 2017. - Т. 27, № 1. - С. 5-10.

5. Сонич Г. Ф. Иркутская государственная экономическая академия (исторический очерк) / Г. Ф. Сонич. Иркутск : Изд-во ИГЭА, 1996. - 288 с.

6. Иркутская государственная экономическая академия: в цифррах, фрактах, мнениях / сост. Н. В. Деренко, О. Ю. Оношко. - Иркутск : Изд-во ИГЭА, 2000. - 43 с.

7. Сонич Г. Ф. Иркутская государственная экономическая академия: история в лицах / Г. Ф. Сонич. Иркутск : Изд-во ИГЭА, 2000. - 400 с.

8. Гомбалевский В. А. Наука в Иркутской государственной экономической академии в прошлом и настоящем : крат. ист. очерк / В. А. Гомбалевский, В. И. Самаруха. - Иркутск : Изд-во ИГЭА, 2000. - 238 с.

9. С Нархозом связанные судьбы: очерки, рассказы, эссе / под ред. М. П. Рачкова. - Иркутск : Изд-во БГУЭП, 2010. - 589 с.

10. Суходолов А. П. «Храм науки» или «фрабрика кадров»: к историческим предпосылкам дискуссии об опорном университете Байкальского региона / А. П. Суходолов, Д. Я. Майдачевский. - Иркутск : Изд-во БГУ, 2017. -92 c.

11. Ширяев Ф. Университет в Иркутске. Историческая справка / Ф. Ширяев / / Иркутский университет и общество / сост. С. И. Гольдфрарб. - Иркутск : Репроцентр А1, 2013. - С. 52-67.

12. Новиков П. А. Гражданская война в Восточной Сибири / П. А. Новиков. - М. : Центрполиграф, 2005. $415 \mathrm{c}$

13. Гольдфарб С. Иркутский государственный университет: Хроника событий: 1918-1998 / С. Гольдфарб, Н. Щербаков. - Иркутск : КП-Байкал : Изд-во Иркут. ун-та, 1998. - 304 с.

14. Иркутский государственный университет им. А. А. Жданова: крупнейший учебно-методический и научный центр Восточной Сибири : крат. ист. очерк / ред. В. Г. Фридман. - Иркутск, 1978. - 170 с.

15. Нестерович А. А. Иркутский государственный университет - первенец вузовской науки Восточной Сибири (1918-1998) / А. А. Нестерович. - Иркутск : КП-Байкал : Изд-во Иркут. ун-та, 1998. - 112 с.

16. География Сибири в начале XXI века : в 6 т. / гл. ред. В. М. Плюснин, отв. ред. Ю. А. Зуляр, В. А. Снытко. - Новосибирск : Гео, 2014. - Т. 1 : Историческая география. - 318 с.

17. Казарин В. Н. Теоретические и практические аспекты административных и территориальных преобразований в Восточной Сибири в 20-30-е годы XX века / В. Н. Казарин // Известия Иркутской государственной экономической академии. - 2005. - № 3-4 (44-45). - С. 95-103.

18. Суходолов А. П. Научно-образовательный потенциал и стратегия развития Байкальского университета (к 85-летию вуза) / А. П. Суходолов / / Известия Иркутской государственной экономической академии. 2015. - T. 25, № 2. - C. 187-195.

\section{REFERENCES}

1. Sukhodolov A. P., Maidachevsky D. Ya. The «pragmatic turn» in the university education development. Izvestiya Irkutskoi gosudarstvennoi ekonomicheskoi akademii = Bulletin of Irkutsk State Economics Academy, 2016, vol. 26, no. 2, pp. 167-174. DOI: 10.17150/1993-3541.2016.26(2).167-174. (In Russian).

2. Sukhodolov A. P., Maidachevsky D. Ya. The higher education system of Irkutsk region: a temple of science vs. a personnel factory (1920's-1930's). Izvestiya Irkutskoi gosudarstvennoi ekonomicheskoi akademii = Bulletin of Irkutsk State Economics Academy, 2016, vol. 26, no. 4, pp. 525-533. DOI: 10.17150/2500-2759.2016.26(4).525533. (In Russian).

3. Sukhodolov A. P., Maidachevsky D. Ya. The higher education system of Irkutsk region: a temple of science vs. a personnel factory (1920's-1930's). Izvestiya Baykal'skogo gosudarstvennogo universiteta = Bulletin of Baikal State University, 2016, vol. 26, no. 5, pp. 693-704. DOl: 10.17150/2500-2759.2016.26(5).693-704. (In Russian).

4. Sukhodolov A. P., Maidachevsky D. Ya. Economics education in Russia and in Irkutsk Region: response to modernization challenges of the mid-20 th century. Izvestiya Baykal'skogo gosudarstvennogo universiteta $=$ Bulletin of Baikal State University, 2017, vol. 27, no. 1, pp. 5-10. DOI: 10.17150/2500-2759.2017.27(1).5-10. (In Russian).

5. Sonich G. F. Irkutskaya gosudarstvennaya ekonomicheskaya akademiya (istoricheskii ocherk) [Irkutsk State Economic Academy (a historical sketch)]. Irkutsk State Economics Academy Publ., 1996. 288 p.

6. Derenko N. V., Onoshko O. Yu. (eds.). Irkutskaya gosudarstvennaya ekonomicheskaya akademiya: $v$ tsifrakh, faktakh, mneniyakh [Irkutsk State Academy of Economics: in numbers, facts, opinions]. Irkutsk State Economics Academy Publ., 2000. 43 p.

7. Sonich G. F. Irkutskaya gosudarstvennaya ekonomicheskaya akademiya: istoriya $v$ litsakh [Irkutsk State Economic Academy: History in Faces]. Irkutsk State Economics Academy Publ., 2000. 400 p. 
8. Gombalevskii V. A., Samarukha V. I. Nauka v Irkutskoi gosudarstvennoi ekonomicheskoi akademii v proshlom i nastoyashchem [Science in Irkutsk State Economic Academy in past and present]. Irkutsk State Economics Academy Publ., 2000. 238 p.

9. Rachkov M. P. (ed.). S Narkhozom svyazannye sud'by [The fates, related to BSUEL]. Irkutsk, Baikal State University of Economics and Law Publ., 2010. 589 p.

10. Sukhodolov A. P., Maidachevsky D. Ya. «Khram nauki» ili «fabrika kadrov»: k istoricheskim predposylkam diskussii ob opornom universitete Baikal'skogo regiona [ "The Sanctuary of Sciences» or "Personnel Factory»: Historical Background of the Discussion about the Basic University of Baikal Region]. Irkutsk, Baikal State University Publ., 2017. 92 p.

11. Shiryaev F. University in Irkutsk. Historical background. In Gol'dfarb S. (ed.). Irkutskii universitet i obshchestvo [Irkutsk University and the Society]. Irkutsk, Reprotsentr A1 Publ., 2013, pp. 52-67. (In Russian).

12. Novikov P. A. Grazhdanskaya voinav Vostochnoi Sibiri [Civil War in Eastern Siberia]. Moscow, Tsentrpoligraf Publ., 2005. 415 p.

13. Gol'dfarb S., Shcherbakov N. Irkutskii gosudarstvennyi universitet: khronika sobytii: 1918-1998 [Irkutsk State University: chronicle of events (1918-1998)]. Irkutsk, KP-Baikal Publ., Irkutsk State University Publ., 1998. 304 p.

14. Fridman V. G. (ed.). Irkutskii gosudarstvennyi universitet im. A. A. Zhdanova: krupneishii uchebno-metodicheskii i nauchnyi tsentr Vostochnoi Sibiri [A. A. Zhdanov Irkutsk State University: the Biggest Educational and Methodological Centre of Eastern Siberia]. Irkutsk, 1978. 170 p.

15. Nesterovich A. A. Irkutskii gosudarstvennyi universitet - pervenets vuzovskoi nauki Vostochnoi Sibiri (1918-1998) [lrkutsk State University — Firstling of the University Research in Eastern Siberia (1918-1998)]. Irkutsk, KP-Baikal Publ., Irkutsk State University Publ., 1998. 112 p.

16. Plyusnin V. M., Zulyar Yu. A., Snytko V. A. (eds.). Geografiya Sibiri v nachale XXI veka [Geography of Siberia at the Turn of the XXI Century]. Novosibirsk, Geo Publ., 2014. Vol. 1. 318 p.

17. Kazarin V. N. Theoretical and Practical Aspects of Administrative and Territorial Changes in Eastern Siberia in the 1920s-1930s. Izvestiya Irkutskoi gosudarstvennoi ekonomicheskoi akademii = Izvestiya of Irkutsk State Economics Academy, 2005, no. 3-4 (44-45), pp. 95-103. (In Russian).

18. Sukhodolov A. P. Research and educational potential and Baikal University development strategy (devoted to the $85^{\text {th }}$ anniversary of the university). Izvestiya Irkutskoi gosudarstvennoi ekonomicheskoi akademii = Izvestiya of Irkutsk State Economics Academy, 2015, vol. 25, no. 2, pp. 187-195. DOI: 10.17150/1993-3541.2015.25(2).187195. (In Russian).

\section{Информация об авторе}

Казарин Виктор Николаевич - доктор исторических наук, магистр юриспруденции, профрессор, кафедра конституционного права и теории права, Юридический институт Иркутского государственного университета, 664003, г. Иркутск, ул. Карла Маркса, 1, e-mail: kazarinvik@yandex.ru.

\section{Для цитирования}

Казарин В. Н. Экономическое образование в Восточной Сибири в контексте модернизационных процессов XX века. Размышления над книгой А. П. Суходолова и Д. Я. Майдачевского / В.Н.Казарин // Известия Байкальского государственного университета. - 2018. - T. 28, № 1. - C. 166-173. - DOI: 10.17150/2500-2759.2018.28(1).166-173. - Рец. на кн.: «Храм науки» или «фрабрика кадров»: к историческим предпосылкам дискуссии об опорном университете Байкальского региона / А. П. Суходолов, Д. Я. Майдачевский. - Иркутск : Изд-во БГУ, 2017. - 92 с.

\section{Author}

VictorN. Kazarin - DSc in History, Master of Laws, Professor, Department of Constitutional Law and the Theory of Law, Law Institute, Irkutsk State University, 1 Karl Marx St., 664003, Irkutsk, the Russian Federation, e-mail: kazarinvik@yandex.ru.

\section{For citation}

Kazarin V. N. Economics Education in Eastern Siberia in the Context of Modernization Processes of the $20^{\text {th }}$ Century. Thoughts on the Book by Alexander Sukhodolov and Dmitry Maidachevsky. Izvestiya Baykal' skogo gosudarstvennogo universiteta $=$ Bulletin of Baikal State University, 2018, vol. 28, no. 1, pp. 166173. DOI: $10.17150 / 2500-2759.2018 .28(1) .166-173$. (In Russian). 